\title{
QUALIDADE SOCIAL DA EDUCAÇÃO? BREVE ANÁLISE DO Programa MaIS EduCAÇÃo SÃo PAULO
}

\author{
MAURÍCIO DE SOUSA ${ }^{1}$ \\ MARA Regina de LeMES de SORDI²
}

\begin{abstract}
RESUMO: Este texto analisa o processo de implantação do Programa Mais Educação São Paulo pela Secretaria Municipal de Educação de São Paulo, no período de 2013 a 2016, cujo objetivo central era garantir a qualidade social da educação. Por meio dos pressupostos da abordagem do ciclo de políticas, formulado por Stephen Ball et al. (1994), em especial o contexto de produção, analisamos os atos normativos e os documentos produzidos nesse período. São estudados dois elementos desse programa, a saber: reformulação do sistema de ciclos e a criação de um sistema de monitoramento do processo avaliativo. Concluímos, que esse programa, no tocante à qualidade social da educação, ficou apenas no discurso, pois encontramos uma tendência de aumento das taxas de reprovação e evasão, além do estabelecimento de um sistema de monitoramento e acompanhamento do processo pedagógico do professor, divergindo da concepção de qualidade social fundamentada na participação, diálogo e formação integral do estudante.
\end{abstract}

Palavras-chave: Políticas Públicas Educacionais. Qualidade Social. Educação Básica.

\section{SOCIAL QUALITY OF EDUCATION? BRIEF ANALYSIS OF THE MORE EDUCATION PROGRAM OF SÃO PAULO}

ABSTRACT: This text analyzes the implementation process of the More Education São Paulo Program by the Municipal Department of Education of São Paulo, from 2013 to 2016, whose central objective was to guarantee the social quality of education. Through the assumptions of the policy cycle approach, formulated by Stephen Ball et al. (1994), especially the production context, we analyze the normative acts and the documents produced in that period. Two elements of this program are studied, namely: reformulation of the cycle system and creation of a monitoring system of the evaluation process. We conclude that this program regarding the social quality of education was only in the discourse, as we found a tendency to increase the rates of disapproval and evasion, in addition to establishing a system for monitoring the teacher's pedagogical process, diverging from the conception of social quality based on the participation, dialogue and integral formation of the student.

Keywords: Public Educational Policies. Social Quality. Basic Education.

1 Mestre em Ciências Sociais pela Universidade de São Paulo (USF) Doutorando em Educação pela UNICAMP/Laboratório de Observação e Estudos Descritivos (LOED). 2 Professora da Faculdade de Educação da Universidade Estadual de Campinas -UNICAMP 


\section{¿CALIDAD SOCIAL DE LA EDUCACIÓN? BREVE ANÁLISIS DEL PROGRAMA MÁS EDUCACIÓN SÃO PAULO}

RESUMEN: Este texto analiza el proceso de implantación del Programa de Educación para la Ciudad de São Paulo, en el período de 2013 a 2016. En especial el contexto de la producción, el análisis de los aspectos normativos y los documentos producidos en el período. Se han estudiado dos elementos de ese programa: la reformulación del sistema de ciclos y la creación de un sistema de monitoreo del proceso evaluativo. Concluimos, que ese programa cuanto a la calidad social de la educación, ha quedado solo en el discurso, puesto que hubo una tendencia de aumento de las tasas de reprobación y evasión, además de un sistema de monitorización y seguimiento del proceso pedagógico del profesor, divergiendo de la concepción de calidad social fundamentada en la participación, diálogo y formación integral del estudiante.

Palabras clave: Políticas Educativas Públicas. Calidad Social. Educación Primaria.

\section{Introdução}

Em 2013, após uma disputa política e eleitoral acirrada, o ex-ministro da educação Fernando Haddad, do Partido dos Trabalhadores, assumiu o cargo de prefeito da cidade de São Paulo. O retorno do Partido dos Trabalhadores ${ }^{3}$ ao comando da maior cidade do país significou a adoção de um novo programa no sistema de ensino municipal intitulado Programa Mais Educação São Paulo, que promoveu algumas mudanças na política educacional do município.

Este texto busca analisar o processo de implantação desse programa, por meio da análise dos textos e atos normativos elaborados pela Secretaria Municipal de Educação de São Paulo (SMESP). Para realizar essa análise utilizamos os pressupostos da abordagem do ciclo de políticas, formulado por Stephen Ball et al. (1994), em especial o contexto de produção da concepção de qualidade da educação contida no Programa Mais Educação São Paulo.

\section{A política como processo}

Uma das grandes dificuldades no estudo das políticas educacionais é a definição do que é política. Para Ball (2002), muitos analistas não conseguem definir claramente o que é política e com isto "o termo política é utilizado para descrever muitas coisas distintas e diferentes em um mesmo 
estudo" (BALL, 2002, p. 20). Continuando a problematização desse conceito, o autor afirma que "dependendo do significado ou possibilidades de significados que outorgamos à política isso afetará como investigamos e como interpretamos o que encontramos" (BALL, 2002, p. 20). Por fim, conclui que a política não é uma "coisa", mas sim processo e resultados.

Partindo dessa concepção de política como processo, Bowe, Ball e Gold (1992) apresentam uma abordagem de análise sobre as políticas públicas, chamada de ciclo de políticas. Nessa abordagem teórica, existem diferentes contextos que se entrecruzam na formulação de uma política. São esses os contextos: contexto de influência "onde normalmente as políticas públicas são iniciadas e os discursos políticos construídos" (MAINARDES, 2006, p. 51). Em seguida, o contexto de produção, no qual temos a materialização da política, por meio de documentos legais, textos políticos, comentários etc. Seguese o contexto da prática "onde a política está sujeita à interpretação e recriação e onde a política produz efeitos e consequências" (MAINARDES, 2006, p. 53). Mais adiante, Ball (1994) acrescenta outros dois contextos: contexto dos resultados ou efeitos e contexto de estratégia política.

Para a compreensão desse contexto de produção do Programa Mais Educação São Paulo, utilizamos a análise dos textos e atos normativos, produzidos pela SMESP, para implantação desse programa. Dessa forma, compreendemos que

[...] os textos são produto de compromissos em várias etapas (e no momento de influência inicial nas micropolíticas da formulação legislativa, no processo parlamentar e nas políticas e micropolíticas dos grupos de interesse). Eles são tipicamente produtos de múltiplas (mas circunscrito) influências e agendas. Existem ações não planejadas, negociadas e oportunizadas dentro do Estado e no processo de elaboração das políticas (BALL, 2002, p. 21).

Nesse contexto de produção dos textos e atos normativos do Programa Mais Educação São Paulo entendemos que as reformas administrativas que vinham ocorrendo, no governo federal brasileiro, desde o início dos anos 1990, influenciaram na elaboração deste programa. Entre essas reformas destacamos as seguintes, descritas por Abrúcio (2011) e Silva e Carvalho (2014):

- Gestão pautada por resultados que gerou uma visão centrada no desempenho, por meio de uma prática orientada por metas, indicadores, monitoramento e avaliação das políticas públicas;

- Criação do Índice de Desenvolvimento da Educação Básica (IDEB) para avaliar e monitorar o desempenho educacional; 
- Criação de mecanismos de accountability e responsabilização, principalmente com a publicização de informações e dados para a sociedade;

- Difusão de uma concepção de nova gestão pública, pautada em concepções da inciativa privada e do mercado, visando melhor desempenho, eficiência e produtividade. Essas transferências de concepções do mercado geram no campo educacional novas perfomatividades e fabricações (Ball, 2010);

- Estabelecimento de um governo eletrônico em que as informações são disseminadas via portais, sistemas e plataformas eletrônicas virtuais.

Além dessas reformas administrativas que afetaram diretamente o serviço público, também nas últimas décadas, tivemos (e temos) o embate de duas visões sobre o conceito de qualidade, descrita pela professora Maria Abadia Silva (2009, p. 219) "no campo econômico, o conceito de qualidade dispõe de parâmetros de utilidade, praticidade e comparabilidade, utilizando medidas e níveis mensuráveis, padrões, rankings, testes comparativos, hierarquização e estandardização próprias do âmbito mercantil".

No entanto, temos uma qualidade social da educação também definida por Silva (2009, p. 225):

\begin{abstract}
A escola de qualidade social é aquela que atenta para um conjunto de elementos e dimensões socioeconômicas e culturais que circundam o modo de viver e as expectativas das famílias e de estudantes em relação à educação; que busca compreender as políticas governamentais, os projetos sociais e ambientais em seu sentido político, voltados para o bem comum; que luta por financiamento adequado, pelo reconhecimento social e valorização dos trabalhadores em educação; que transforma todos os espaços físicos em lugar de aprendizagens significativas e de vivências efetivamente democráticas.
\end{abstract}

Nesse contexto de reformas administrativas do Estado e das reformulações das concepções do que é qualidade teremos a implantação do Programa Mais Educação São Paulo.

\title{
O processo de implantação do Programa Mais Educação São Paulo
}

No mês de abril de 2013, a Secretária Municipal de Educação de São Paulo (SMESP) apresentou o documento "Considerações sobre o currículo e os direitos de aprendizagem e desenvolvimento dos alunos na Rede Municipal de São Paulo: contexto e perspectivas" (SÃO PAULO, 
2013c). Esse documento foi dividido em duas partes: a primeira apresentava o contexto político, econômico e social do país e da cidade de São Paulo, nos últimos 20 anos, destacando os avanços ocorridos neste período como: a consolidação da democracia, criação programas sociais como: Bolsa Família e Programa de Aceleração ao Crescimento (PAC) que contribuíram para a redução da miséria no país. No campo educacional, o documento destaca como principal avanço a garantia do acesso das crianças à educação básica, ressaltando ainda as dificuldades de acesso à educação infantil e permanência no ensino médio.

Ainda na primeira parte do documento são destacados os desafios para a educação na cidade de São Paulo, que são os seguintes: garantia da educação integral na educação infantil e ensino fundamental; abertura das escolas para as comunidades; educação profissional e tecnológica; elevação da escolaridade para jovens e adultos; valorização dos educadores; garantia da gestão democrática; apoio à formação dos gestores em educação e educação para vida em uma cultura de paz. Na segunda parte do documento, que tem como subtítulo "Qualidade social da educação como direito", são descritos os aspectos pedagógicos para que a educação municipal paulista enfrente os desafios descritos anteriormente que são: o currículo numa perspectiva interdisciplinar, a garantia da aula como o espaço primordial de desenvolvimento das aprendizagens do aluno, a formação contínua do professor, a avaliação para aprendizagem (destacando dois pontos: a necessidade do acompanhamento e monitoramento pelos gestores e comunidade, além da articulação entre as avaliações da sala de aula, externa e institucional) e por fim, a garantia da alfabetização das crianças até os oito anos de idade conforme determinava o Programa Alfabetização na Idade Certa (PNAIC) do governo federal.

Compreendendo a política como texto (BALL, 2002), é importante ressaltar que nesse primeiro documento dessa gestão são apresentados alguns indícios possíveis que seriam adotados por esse governo nos próximos quatro anos, são eles: alinhamento das políticas educacionais do governo federal (PNAIC e Programa Mais Educação); qualidade social da educação (mas sem uma definição clara do termo); ênfase da avaliação para aprendizagem (foco no acompanhamento e monitoramento do trabalho realizado na sala de aula) e revisão curricular na perspectiva da interdisciplinaridade. Continuando o processo de reestruturação da Rede Municipal de Ensino de São Paulo, em agosto do mesmo ano, a SMESP, a partir das reflexões dos seus técnicos em relação ao documento anterior, lançou novo documento para consulta pública dos profissionais de educação da rede, via internet.

Esse novo documento trazia a nova proposta de reorganização do ensino da Rede Municipal 
de Ensino São Paulo que seria vigente até o final desse governo. Com o título "Programa de Reorganização Curricular e Administrativa, Ampliação e Fortalecimento da Rede Municipal de Ensino de São Paulo" (SÃO PAULO, 2013f) apresentava as seguintes mudanças: nova organização da escola em ciclos, avaliação para aprendizagem, formação dos profissionais de educação, educação integral e gestão democrática.

Passado o período de consulta pública dos profissionais da educação, em outubro de 2013, foi publicado o Decreto $\mathrm{n}^{\circ} 54.452$ que instituiu o Programa de Reorganização Curricular e Administrativa, Ampliação e Fortalecimento da Rede Municipal de Ensino - Mais Educação São Paulo (SÃO PAULO, 2013a) e a Portaria no 5.930 que apresentava as especificações deste novo programa da SMESP (SÃO PAULO, 2013b). De acordo com esses dois atos normativos, verificamos que os apontamentos realizados na consulta pública não resultaram em nenhuma mudança significativa ao documento de agosto de 2013. Assim, a instituição do Programa Mais Educação São Paulo, que seria a diretriz do ensino municipal, no período de 2013 a 2016, trouxe as seguintes mudanças a para essa rede de ensino:

1- $\quad$ Alinhamento com as políticas do governo federal, como por exemplo, com a utilização do IDEB como um dos instrumentos para a melhoria da qualidade social da educação e alfabetização de todas as crianças até o 30 ano do ensino fundamental, como determina o Pacto Nacional pela Alfabetização na Idade Certa (PNAIC);

2- Revisão dos ciclos de aprendizagem, substituindo os dois ciclos anteriores por três

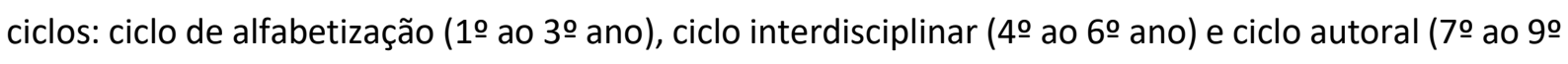
ano);

3- Utilização dos conceitos numéricos: 0 (zero) a 10 (dez) a partir do 4o ano ao 9o ano;

4- Reprovação dos alunos ao final do ciclo de alfabetização (3o ano) e a partir do 6으 ano em todos os anos escolares.

5- Consolidadas essas mudanças, por meio dos atos normativos, seriam essas medidas para a garantia da qualidade social da educação municipal paulistana? É o que vamos analisar adiante.

\section{O Programa Mais Educação São Paulo e a construção da qualidade social}

No processo de estabelecimento dessa nova mudança do ensino municipal de São Paulo o 
termo qualidade social da educação, como destacamos anteriormente, passou a ser utilizado. Porém qual a concepção de qualidade está presente nesses documentos? Identificamos neles que um dos fatores que justificaria a implantação desse Programa Mais Educação São Paulo seria a melhoria do IDEB como destacamos no fragmento abaixo:

Os objetivos de tais mudanças são os de promover a melhoria da qualidade social da Educação Básica e, consequentemente, dos seus indicadores de qualidade, entre eles o IDEB, de forma que se realize eficaz interação entre as diferentes etapas e modalidades - Educação Infantil, Ensino fundamental, Educação de Jovens e Adultos e Ensino Médio - com lógica, objetivos e ações que as articulem (SÃO PAULO, 2013d, p. 19).

De acordo com o Decreto $n^{\circ} 54.452$, que instituiu o Programa Mais Educação São Paulo, a qualidade social seria alcançada a partir de mudança em cinco eixos: infraestrutura, currículo (reorganização dos ciclos de aprendizagem), avaliação, formação do educador e gestão. Passamos a analisar dois desses eixos: a organização da escola em ciclos e a avaliação.

\section{A escola organizada por ciclos ou seriada?}

O Programa Mais Educação São Paulo, ao propor a reorganização dos ciclos, recuperou as discussões de meados dos anos 1990 que apresentava a oposição entre ciclos e aprovação automática (cuja finalidade é a aprovação dos alunos independente de alcançar ou não as aprendizagens necessárias para avançar na sua escolarização). Esse debate, de acordo com alguns autores (ALAVARSE, 2009; FREITAS, 2003; JEFFREY, 2011; MAINARDES, 2007), é resultado da substituição da concepção da escola organizada em ciclos (de aprendizagem ou formação humana) por uma política de aprovação automática.

Dessa forma, a reorganização dos ciclos, proposta pelo Programa Mais Educação São Paulo para a rede municipal de ensino, possibilitava uma maior retenção nos anos, e não apenas ao final de cada ciclo. Lembramos que o sistema de ciclos foi adotado na rede municipal de ensino da cidade de São Paulo, em 1992, pela então prefeita, Luiza Erundina, também do Partido dos Trabalhadores (PT). Na época essa proposta inovadora também foi adotada em outras cidades brasileiras, principalmente as administradas pelo PT, no início dos anos de 1990 (MAINARDES, 2007) e visava a garantia da qualidade social, por meio do acesso, permanência e redução da "pedagogia da repetência" tão presente no sistema educacional brasileiro (RIBEIRO, 1991). 
Naquele período, 1992, na Rede Municipal de Ensino de São Paulo, foram adotados três ciclos

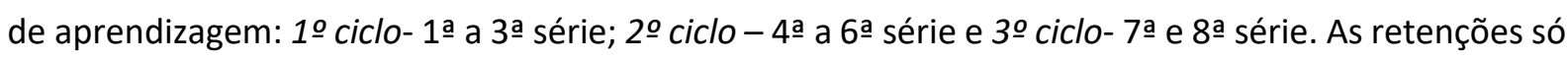
ocorreriam ao final de cada ciclo. Em 1998, ocorreu uma alteração no sistema de ciclos da rede municipal, seguindo a Lei de Diretrizes e Bases da Educação Nacional, de 1996, e acompanhando a nova estrutura de organização do sistema de ensino da Rede Estadual de São Paulo, os ciclos de aprendizagem na rede municipal passaram a ser dois: ciclo I - 1a a 4ạ série e ciclo ll- 5a a 8a série.

Portanto, o sistema de ciclos estava completando vinte anos na Rede Municipal de Ensino de São Paulo quando o Programa Mais Educação São Paulo foi iniciado e buscava "recuperar" a proposta originária de 1992 com três ciclos, como novos mecanismos de garantia da qualidade social da educação. Na imagem abaixo vemos como ficou a nova estrutura dos ciclos, com a implantação do Programa Mais Educação São Paulo, em 2013.

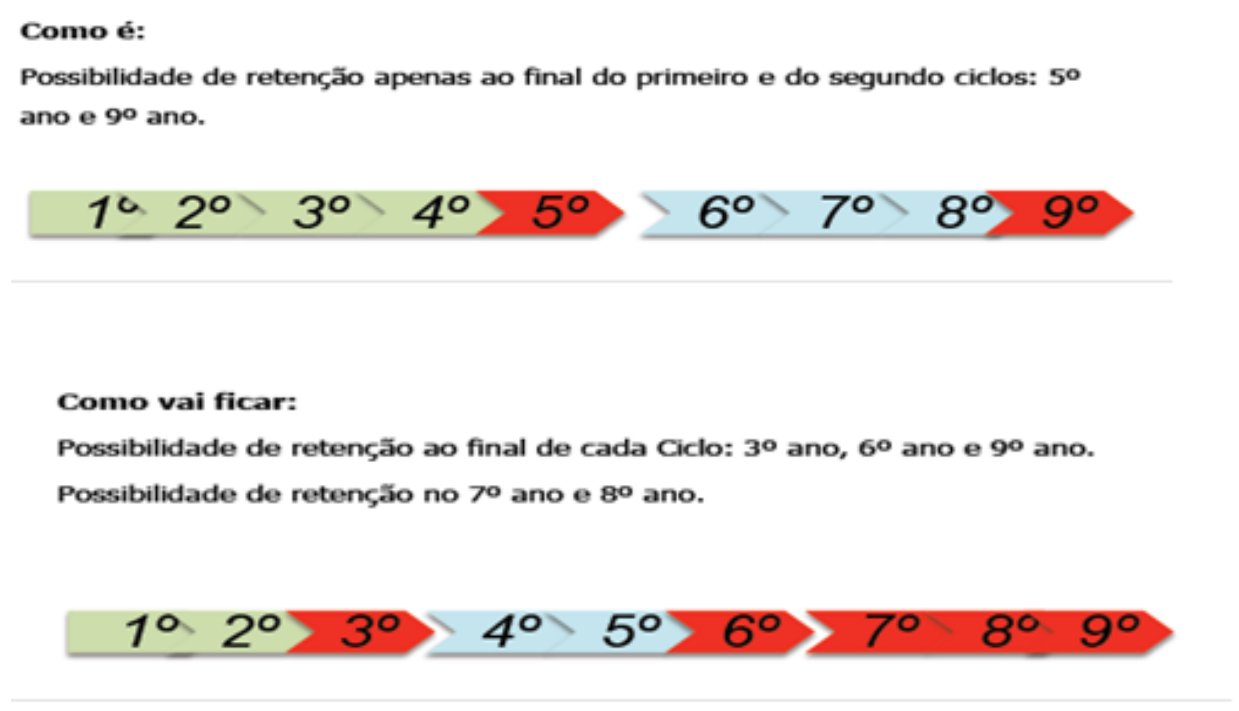

Fonte: São Paulo, 2013f, p. 37.

Essa nova organização da estrutura de ensino pela SMESP reforça a confusão teórica sobre a organização da escola em ciclos e seriada. E mais do que isso difunde uma concepção de educação em que "a ideia de repetência como uma medida apropriada a um sistema educacional que se pretende de qualidade, admitindo-se a seletividade e a exclusão como inerentes à dinâmica escolar e social" (SOUSA, 2014, p. 412). Além disso, é importante ressaltar que essa nova organização dos "ciclos" veio de encontro à visão de muitos grupos sociais, inclusive de alguns educadores, que acreditavam que a reprovação dos alunos era um dos mecanismos para a melhoria da qualidade da educação. 
[...] parte das propostas apresentadas pelo prefeito Fernando Haddad (PT) vai ao encontro do que reivindicam os professores das escolas públicas: mais poderes dentro das salas de aula. Um forte discurso entre educadores é que os alunos perderam a disciplina porque sabem que a reprovação é quase impossível após a adoção da progressão continuada, em 1992, na gestão Luiza Erundina (então no PT). A proposta de Haddad atende aos professores ao aumentar a possibilidade de retenção das atuais duas para cinco séries do fundamental. O prefeito diz que seu plano visa avaliar melhor e dar mais apoio pedagógico ao aluno, o que evitará que ele não saiba o conteúdo (e, consequentemente, reprove) (TAKAHASHI, 2013).

Essa mesma visão foi descrita por Jacomini (2010) ${ }^{4}$ em sua pesquisa sobre o sistema de ciclos e a reprovação escolar. A pesquisadora realizou cinquenta e seis entrevistas (sendo quatorze pais e quatorze alunos) em duas escolas da Rede Municipal de Ensino de São Paulo, em meados dos anos 2000, e também descreveu essa relação entre reprovação e qualidade da educação.

Por acreditarem que a reprovação é uma forma eficiente de garantir uma aprendizagem melhor, alguns pais e alunos - mesmo percebendo que muitas vezes o aluno continua com baixo desempenho escolar após ter sido reprovado - referem-se à reprovação como "redentora". Em certo sentido, eles depositam nela a expectativa de realização de um ensino de qualidade (JACOMINI, 2010, p. 902).

Entretanto, quando analisados os dados da Rede Municipal de Ensino de São Paulo, após a implantação do Programa Mais Educação São Paulo, observamos a tendência do aumento das taxas de reprovação e evasão, no ensino fundamental II (5a série a 8a série/ 6 ao 9aano), pois a partir do 60 ano a reprovação passou a ser anual. Na Tabela 1, apresentamos os dados da série histórica desde 1992 a 2015, ano que foi adotado o sistema de ciclos nesta rede de ensino.

4 Pesquisa semelhante também foi realizada por Glória (2003), que apresenta a visão dos alunos sobre a escola de ciclos na cidade de Belo Horizonte, em que estes também fazem a associação da prática da não retenção como uma educação de baixa qualidade. 
Tabela 1 - Percentual de reprovação e evasão no ensino fundamental II da rede de ensino do município de São Paulo (1992 a 215)

\begin{tabular}{|c|c|c|}
\hline & \multicolumn{2}{|c|}{ Ensino fundamental II (60 ao 9o ano) } \\
\hline & Reprovação & Evasão \\
\hline 1992 & 4,25 & 5,97 \\
\hline 1993 & 8,37 & 7,48 \\
\hline 1994 & 12,24 & 6,13 \\
\hline 1995 & 12,96 & 6,4 \\
\hline 1996 & 11,9 & 5,25 \\
\hline 1997 & 9,68 & 2,18 \\
\hline 1998 & 6,94 & 2,81 \\
\hline 1999 & 4,2 & 2,73 \\
\hline 2000 & 5,1 & 2,7 \\
\hline 2001 & 4,43 & 1,98 \\
\hline 2002 & 3,89 & 1,99 \\
\hline 2003 & 4,43 & 1,82 \\
\hline 2004 & 5,43 & 2,02 \\
\hline 2005 & 5,26 & 1,11 \\
\hline 2006 & 8,21 & 1,97 \\
\hline 2007 & 9,23 & 1,59 \\
\hline 2008 & 7,15 & 1,59 \\
\hline 2009 & 5,7 & 1,7 \\
\hline 2010 & 5,23 & 1,66 \\
\hline 2011 & 5,15 & 1,78 \\
\hline 2012 & 3,11 & 1,95 \\
\hline 2013 & 3,28 & 2,48 \\
\hline 2014 & 9,53 & 3,54 \\
\hline 2015 & 7,51 & 2,73 \\
\hline
\end{tabular}

Fonte MEC/INEP (2016).

Como se vê, as taxas de reprovação a partir dos anos 2000, em especial depois de 2008, vinham em queda ano a ano, atingindo a menor média, em 2012, com 3,11\%. Entretanto, em 2014 e 2015, já implantado o novo sistema de ciclo na rede, inicia a tendência de aumento dessa taxa. Mesmo com a diminuição da reprovação em 2015, não podemos negar o aumento expressivo dessa taxa no ensino fundamental II pós Programa Mais educação São Paulo. Essa mesma situação se observa em relação às taxas de evasão, visto que nos anos de 2014 e 2015 ocorreram as maiores taxas de evasão pós anos 2000 .

Outro dado importante é observarmos a tendência de aumento das taxas de reprovação em 
cada uma das séries após o processo de implantação do Programa Mais Educação São Paulo. Na Tabela 2 são apresentados os dados de reprovação em cada série de 2012 a 2015.

Tabela 2 - Taxas de reprovação das escolas municipais de São Paulo- período 2012 a 2015

\begin{tabular}{cccccccccc}
\hline & 10 ano & 20 ano & 3o ano & 40 ano & 50 ano & 60 ano & 70 ano & 80 ano & 9o ano \\
\hline $\mathbf{2 0 1 2}$ & 0,7 & 0,6 & 0,5 & 1,1 & 3,4 & 1,7 & 2,2 & 2,8 & 5,8 \\
$\mathbf{2 0 1 3}$ & 1,0 & 0,8 & 0,8 & 0,8 & 5,7 & 1,2 & 2,0 & 2,8 & 6,8 \\
$\mathbf{2 0 1 4}$ & 0.7 & 0.6 & 8.4 & 0.8 & 1,0 & 11.8 & 8.4 & 11.1 & 9,0 \\
$\mathbf{2 0 1 5}$ & 0,6 & 0,7 & 7,2 & 0,7 & 1,0 & 7,8 & 13,2 & 7,5 & 6,0 \\
\hline
\end{tabular}

Fonte: MEC/INEP (2016).

A partir desses dados, entendemos que se um dos fundamentos para a garantia da qualidade social da educação é a permanência do aluno, o que observamos pelos dados demonstrados é que esta tendência não está ocorrendo a partir de 2014, após a redefinição dos "ciclos" na Rede Municipal de Ensino de São Paulo. Diversos estudos (FERRÃO; BELTRÃO; SANTOS, 2002; GLÓRIA, 2003; PARO, 2001, PATTO, 1998; REBELO, 2009; VIÈGAS, 2002) apontaram que a "pedagogia da repetência" (RIBEIRO, 1991), ou "cultura da seletividade" (ARROYO, 2000) não significa a garantia da aprendizagem dos alunos. Ao contrário, podemos identificar na reprovação elementos prejudiciais à escolarização do aluno como descreve Rebelo (2009, p. 43-44),

[...] abundância de estudos que, desde o século passado até ao presente, mostram que a retenção tem efeitos nefastos, sobretudo a longo prazo, sendo o abandono escolar o mais evidente e consensual [...] reprovar os alunos, medida que sanciona e que, em maior ou menor grau e dependendo do nível escolar e da idade em que os alunos se encontrem, pode diminuir a sua autoestima, revoltá-los, desinteressá-los pela escola e demovê-los do empenhamento na aprendizagem.

Também em relação ao desempenho dos alunos, alguns estudos indicam que não foram encontramos evidências que afirmem que os alunos que frequentam as escolas seriadas têm melhor desempenho que os alunos de sistema de ensino com prática de não-reprovação. No estudo realizado por Ferrão, Beltrão e Santos (2002) encontrou-se, a partir dos dados dos alunos das escolas públicas dos estados de São Paulo e Minas Gerais no Sistema de Avaliação da Educação Básica (SAEB) de 1999,

[...] não foi encontrada evidência de que o desempenho acadêmico dos alunos com defasagem idade-série seja inferior ao desempenho dos alunos em idade adequada por causa do regime de organização do ensino em vigor na escola que ele frequenta. Também não foi encontrada evidência de que 
alunos desfavorecidos socioeconomicamente que estudam em escolas com promoção automática tenham desempenho inferior aos seus colegas (p. 69).

Em outra pesquisa Alavarse (2007, p. 180 apud SOUSA, 2007, p. 40) observou a mesma tendência ao examinar os dados da Prova Brasil e SAEB em relação ao desempenho dos alunos de escolas em ciclos e seriadas:

[...] não há indicadores que sustentem que os ciclos, ou a não reprovação, tenham produzido uma erosão na qualidade de ensino. A questão ciclos ou séries? Leva-nos, pelos dados apresentados, a recolocar o problema de que a democratização do ensino, entendida como estabelecimento de determinados patamares de desempenho ainda está colocada em qualquer

Por fim, ainda sobre o desempenho dos alunos, dentro das limitações e do contexto socioeconômico e das escolas que foi realizada a pesquisa, na pesquisa de Almeida (2009, p. 148) acabou concluindo que "[...] os índices médios de desempenho foram bons para alguns pólos; no nosso caso, para as escolas de organização cicladas evidenciaram-se melhores resultados do que para as não cicladas". Isso significa que a aprendizagem do aluno não se garante via política de reprovação, mas a partir de prática pedagógica que

[...] vai ao encontro das necessidades dos alunos, o sucesso escolar destes aumenta; as práticas educativas, onde estão incluídas estratégias de prevenção e de intervenção, devem orientar-se pela teoria e pela investigação empírica; as respostas dos alunos à intervenção devem ser cuidadosamente acompanhadas e supervisionadas, para que atividades educativas e intervenções falhadas possam ser ainda corrigidas ou eliminadas. Tomando em consideração a evidência empírica existente, "é essencial passar para além da questão de "reter ou promover?", colocando, de preferência, a ênfase no modo "como promover a competência social e acadêmica dos alunos (REBELO, 2009, p. 48).

Dessa forma, entendemos que a SMESP perdeu a possibilidade de realmente proporcionar uma discussão com toda a comunidade escolar sobre as potencialidades que a escola organizada em ciclos possibilita, como descreve Mainardes e Stremel (2011, p. 53):

a) as propostas de organização da escolaridade em ciclos a reprovação é eliminada total ou parcialmente; b) investe-se na aprendizagem como processo contínuo; c) as notas são eliminadas e substituídas por critérios de avaliação que buscam valorizar o processo de aprendizagem dos alunos (e não apenas o produto); d) os registros da avaliação (pareceres, fichas, relatórios) são qualitativamente superiores à utilização de notas; e) dissemina-se a ideia de que as informações obtidas por meio da avaliação 
devem ser empregadas como ponto de partida para o planejamento de intervenções e da reorientação do processo ensino-aprendizagem.

Por fim, "dentre todas as práticas e rotinas escolares, aquela que mais diretamente é "abalada" com a implantação dos ciclos é a avaliação, sendo sua re-significação na prática escolar necessária para tornar a realidade a reorganização do processo educativo" (SOUSA, 2007, p. 35). Assim, o Programa Mais Educação São Paulo tinha como objetivo rever o sistema de avaliação, visando criar melhores mecanismos de acompanhamento e intervenções das aprendizagens dos alunos, como demonstra a passagem abaixo.

\begin{abstract}
A organização de formas de progressão continuada, no interior dos Ciclos Interdisciplinar e Autoral, é compreendida como construção de um processo contínuo de conhecimentos e habilidades que supõe um sistema de avaliação que visa a referenciar intervenções pedagógicas, combater a repetência, todas as formas de aprovação automática e os fracassos escolares, por meio de acompanhamento e orientação ao longo do desenvolvimento da aprendizagem [...]. Atualmente, a falta de articulação das ações de avaliação gera dificuldades para a reelaboração de estratégias de ensino por parte dos professores (SÃO PAULO, 2013f, p. 26).
\end{abstract}

Entretanto, o que podemos observar, em especial a partir das taxas de retenção e evasão, é que esse "novo" sistema de avaliação não significou a melhoria das intervenções pedagógicas, como a redução do fracasso escolar, ao contrário, entendemos que houve uma tendência a reforçar uma educação que reproduz

[...] processos seletivos como legitimadores da aprendizagem dos promovidos e da não aprendizagem dos reprovados. Assim, ao não oferecer oportunidades de aprendizagem a todos, a escola reproduz diferenças sociais como se fossem individuais e a avaliação escolar é o principal procedimento para legitimar a seleção por meio da promoção e da reprovação (JACOMINI, 2010, p. 916).

Assim a avaliação ficou centrada no resultado das aprendizagens - o produto final - e não no processo - na melhoria das intervenções e das práticas educativas, por isto a necessidade de investimento em um sistema de acompanhamento e monitoramento da avaliação que passamos a analisar.

\title{
A avaliação para aprendizagem ou um sistema de monitoramento?
}

Para analisar o sistema de avaliação instituído pelo Programa Mais Educação São Paulo, além 
dos documentos citados anteriormente, a SMESP lançou outros documentos elaborados pelo seu Departamento de Orientações Técnica Pedagógica, chamados de "Subsídios", cujo objetivo era trazer novas orientações e reflexões para implementação do programa. Esses documentos foram encaminhados para todos os professores e gestores da rede com o objetivo de serem discutidos durante as reuniões pedagógicas e horários de formação coletiva.

Todos os cinco "Subsídios" discorrem sobre a avaliação, entretanto, dois desses documentos retratam apenas o tema avaliação: "Subsídios 2 - Sistema de Gestão Pedagógica - SGP" (SÃO PAULO, 2014b) e a avaliação para a aprendizagem e "Subsídios 4 - Avaliação para aprendizagem: externa e em larga escala" (SÃO PAULO, 2015b).

Além desses "Subsídios" foram publicadas no Diário Oficial do Município duas orientações técnicas sobre a temática da avaliação, a saber: "Nota Técnica 22 - Sobre a avaliação para a aprendizagem no ensino fundamental, incluindo a modalidade educação de jovens e adultos e no ensino médio" (SÃO PAULO, 2013e) e “Orientação Normativa 01/13- Avaliação na educação infantil: aprimorando os olhares" (SÃO PAULO, 2014c).

De acordo com todos esses documentos oficiais, a avaliação é um dos elementos centrais para se conseguir a almejada qualidade social da educação. Dessa forma, a avaliação para a aprendizagem é definida como "[...] uma forma de enfatizar, a todo o momento, que quando se avalia bem o aluno aprende melhor; e que o aluno e o professor podem ampliar o conhecimento de si, de seu processo de estudos, das disciplinas e da reflexão sobre suas habilidades (SÃO PAULO, 2014b, p. 10).

Esses documentos deixam claro que a função da avaliação para a aprendizagem é servir para a tomada de decisão pelo professor, permitindo rever suas ações pedagógicas e garantir o direito de aprendizagem do aluno. Dessa forma, esses documentos buscam orientar o professor nas seguintes questões: por que avaliar? para que avaliar? o que avaliar? como avaliar?

Além disso, todo o processo avaliativo tem que ser publicizado para conhecimento dos estudantes e das famílias. Nesse sentido, a SMESP justifica a importância da implantação de um sistema de acompanhamento do processo pedagógico, chamado de Sistema de Gestão Pedagógico (SGP), instituído pela Portaria $n^{\circ}$ 1224, em 14 de fevereiro de 2014 (SÃO PAULO, 2014a). Trata-se de um sistema informatizado complexo, em que o professor, por meio de um programa conectado à internet, passa a registrar todo o seu processo pedagógico que inclui desde o planejamento anual, o 
conteúdo das aulas, a frequência do aluno e os instrumentos avaliativos.

Por meio desse sistema são gerados os boletins contendo as notas e frequência dos estudantes e as famílias têm acesso via internet. Nesse boletim também são indicadas as recomendações do professor e da gestão em relação ao desempenho do estudante. Além desses registros, os estudantes têm a possibilidade de inserir comentários para melhorar a sua aprendizagem. Novamente temos a utilização dos recursos tecnológicos para a publicização dos documentos oficiais, demostrando que existe um diálogo entre escola e família.

Ademais das ações pedagógicas do professor, do acesso aos boletins pelas famílias o SGP concentra todas as informações da SMESP que podem "ser acessadas e analisadas pelos professores, gestores escolares, DRES e SME na forma de relatórios, gráficos, planilhas ou tarjeta, que sintetizam a trajetória dos alunos, turmas, anos ou ciclos, escolas ou grupos de escolas" (SÃO PAULO, 2014b, p. 19).

O SGP é um recurso tecnológico de acompanhamento e monitoramento do processo pedagógico da escola que, de acordo com a SMESP, é um recurso tecnológico que possibilitaria dar "sentido às políticas públicas em prol da qualidade social da educação" (SÃO PAULO, 2014b, p. 19). Concomitante às avaliações internas, monitorado pelo SGP, o Programa Mais Educação previa um diálogo com as avaliações externas, que de acordo com a coordenadora do Núcleo de Avaliação da SMESP:

Nossa perspectiva de avaliação para a aprendizagem, consideramos que o diálogo entre as avaliações internas e externas potencializam o uso dos seus resultados quando estes se tornam objetos de reflexão para a tomada de decisão futura em relação às aprendizagens conquistadas e aquelas que ainda precisam ser consolidas" (CATALANI, 2015, p. 38).

Isso significa que, dentro dessa concepção de avaliação para a aprendizagem, a avaliação externa tem um papel importante, como fornecedora de dados sobre os avanços das aprendizagens dos alunos. Dessa forma, além das avaliações externas do governo federal, a SMESP continuou oferecendo uma avaliação externa bimestral, via SGP, nas disciplinas de Língua Portuguesa - foco na leitura - e Matemática - foco na resolução de problemas, de caráter facultativo para as escolas.

Entretanto, em maio de 2015, a SMESP criou um sistema próprio de avaliação externa, chamado Prova Mais Educação (SÃO PAULO, 2015a), obrigatório para todas as unidades escolares que avaliaria as disciplinas de Português e Matemática do 3 o ao 9o ano. Todos os dados dessas avaliações externas também iriam abastecer o SGP, tornando-se assim um grande sistema de coleta de dados. 
Porém, no decorrer desse governo (2013-2016), esses dados não foram utilizados para tomada de decisões, ou seja, não tivemos nenhuma ação pedagógica, promovida pela SMESP, que se remeteu a esses dados.

É interessante ressaltar que os próprios documentos elaborados pela SMESP e descritos nesse texto criticam a visão da avaliação para a coleta de dados. Vejamos alguns exemplos: "[...] a avaliação faz sentido dentro de uma filosofia de educação em função de uma política educacional e do contexto em que s realiza. Caso contrário, torna-se mero instrumento de controle ou instrumento pragmatista" (SÃO PAULO, 2015b, p. 10). Mais adiante outro destaque,

[...] quando um processo de avaliação se finda em si mesmo e sua ação é realizada apenas por formalidade, torna-se inócuo, ou seja, é incapaz de produzir o efeito pretendido. Todo o processo de avaliação deve ter por objetivo final tomada de decisão do avaliador ou do que analisa seus resultados (SÃO PAULO, 2015b, p. 10).

Além do mais, nenhum dos documentos pesquisados buscou definir a avaliação da aprendizagem em uma nova perspectiva democrática e inclusiva como descreve Sousa (2007), ao definir qual a função da avaliação no sistema de ciclos.

[...] O desafio é colocar a avaliação a serviço da democratização da escola, sendo assumida como processo capaz de contribuir para o avanço do conhecimento sobre o contexto em análise, informando sobre a realidade, revelando intencionalidades, evidenciando tendências da prática, produzindo subsídios para a construção de respostas e propostas de intervenção, que potencializem a concretização da escola para todos. O horizonte que se impõe com ciclos é a construção de uma escola de qualidade para todos, para o que também se impõe uma nova organização do trabalho escolar, capaz de provocar uma transformação na cultura classificatória e seletiva hoje dominante no sistema escolar (SOUSA, 2007, p. 35).

Diante dessa redefinição da concepção da avaliação educacional, nos perguntamos a partir dos documentos descritos nesse texto: qual a função do SGP? Qual a concepção de educação para adoção desse recurso tecnológico? Compreendemos que, por um lado, temos um sistema de regulação, monitoramento, publicização e coleta de dados que poderia provocar o controle das ações do professor em sala de aula. De outro lado, toda essa tecnologia para o monitoramento das ações avaliativas do professor em relação aos seus alunos na sala de aula contraria a ideia de autonomia e gestão democrática das escolas, que são elementos essenciais para a garantia da qualidade social da educação. 


\section{Considerações Finais}

Por meio dessa breve análise da implantação do Programa Mais Educação São Paulo, em 2013, pela administração petista, na maior cidade do país, observamos que

[...] a desconstrução dos textos visando a compreensão de seu processo de produção torna-se um importante mecanismo de análise discursiva, na medida em que permite localizar as inconsistências dos textos, os pontos em que transgride os limites dentro dos quais foi construído (SHIROMA et al., 2005, p. 433).

Nesse processo de desconstrução dos documentos do programa de reorganização curricular e administrativo da Rede Municipal de Ensino de São Paulo, encontramos um alinhamento com as reformas administrativas promovidas pelo governo federal nos últimos anos. Como exemplo desse alinhamento, há a utilização dos recursos tecnológicos como forma de publicização e legitimação dos seus atos. Shiroma (2005) discute a importância dos estudos dos documentos oficiais para análise das políticas públicas, descreve que uma das caraterísticas atuais dos governos e instituições públicas e particulares é o uso do recurso de publicização dos documentos oficiais, por meio da internet, como forma de legitimação das suas políticas,

[...] estes documentos são relevantes tanto porque fornecem pistas sobre como as instituições explicam a realidade e buscam legitimar suas atividades, quanto pelos mecanismos utilizados para sua publicização, uma vez que muitos dos documentos oficiais, nacionais e internacionais são, hoje, facilmente obtidos via internet. Talvez resida aí uma das principais explicações para a disseminação massiva de documentos digitais e impressos: popularizar um conjunto de informações e justificativas que tornem as reformas legítimas e almejadas (SHIROMA et al., 2005, p. 429).

A partir das observações da autora, podemos compreender que a consulta pública, via internet, realizada em três momentos no processo de implantação do Programa Mais Educação São Paulo, é um mecanismo que promove certa aparência de diálogo, participação e legitimação. Entretanto, como analisamos após essas três consultas, via internet, não encontramos nenhuma 
alteração relevante ao programa ${ }^{5}$.

Na mesma direção, não encontramos no termo qualidade social da educação, nos documentos analisados, a ideia de construção coletiva do conhecimento, de transformação dos espaços de aprendizagem e de aprofundamento da relação comunidade e escola. Ao contrário, a qualidade é vista como melhoria do desempenho do aluno, seja por meio do monitoramento dos instrumentos de avaliação ou da possibilidade de retenção do aluno. Novamente recorremos à definição de qualidade social proposta por Silva (2009, p. 225), na qual

\begin{abstract}
A qualidade social da educação escolar não se ajusta, portanto, aos limites, tabelas, estatísticas e fórmulas numéricas que possam medir um resultado de processos tão complexos e subjetivos, como advogam alguns setores empresariais, que esperam da escola a mera formação de trabalhadores e de consumidores para seus produtos.
\end{abstract}

Concluímos que o discurso político pode se apresentar como sendo portador de grandes mudanças, mas no entendimento da política como texto e discurso (BALL, 2002), podemos compreender melhor suas contradições e fragilidades. E não encontramos no Programa Mais Educação São Paulo mecanismos para a transformação e emancipação dos estudantes, permitindo que "a educação básica passaria a abraçar a luta pela inserção nos bens culturais, afastando-se da lógica da exclusão e da seletividade [...] um esforço para inserir o tempo de escola num tempo cultural e humanizador [...] que dinamize o conjunto das capacidades humanas" (ARROYO, 1996, p. 56, apud FREITAS, 2008, p. 49).

\title{
Referências
}

ABRÚCIO, F. L. Três agendas, seus resultados e um desafio: balanço recente da administração pública federal brasileira. Desigualdade \& diversidade, Rio de Janeiro, Dossiê, p. 119-142, dez., 2011. Edição Especial.

ALAVARSE, O. M. A organização do ensino fundamental em ciclos: algumas questões. Revista Brasileira de Educação, Rio de Janeiro, v. 14, n. 40, p. 35-50, 2009.

5 Destacamos que esse sistema de consulta via internet continuou sendo utilizado pela SMESP como exemplo: Bolsa Mestrado e Doutorado para os professores, que também não foi implantado. 
ALMEIDA, I. B. Análise do desempenho de escolas públicas cicladas e não cicladas pertencentes ao ensino fundamental. 2009. 247p. Tese (Doutorado em Educação) - Universidade Estadual de Campinas, Campinas, 2009.

ARROYO, M. G. Fracasso/sucesso: um pesadelo que perturba nossos sonhos. Em aberto, Brasília, DF, v. 17, n. 71 , p. 37-40, 2000.

AVELAR, M. Entrevista com Stephen J. Ball: uma análise de sua contribuição para a pesquisa em política educacional. Archivos Analíticos de políticas educativas, Universidad de San Andrés, Argentina, v. 24, n. 24, p. 1-14, 2016.

BALL, S. J. Education reform: a critical and post-structural approach. Buckingham: Open University Press, 1994.

BALL, S. Performatividades e fabricações na economia educacional: rumo a uma sociedade performativa. Educação e realidade, Porto Alegre, RS, v. 35, n. 2, p. 37-55, 2010.

BALL, S. Textos, discursos y trayectorias de la política: la teoría estratégica. Páginas, Córdoba, AR, v. 2, n. 2-3, p. 19-33, 2002.

BOWE, R.; BALL, S.; GOLD. A. Reforming education \& changing schools: case studies in policy sociology. London: Routledge, 1992.

CATALANI, E. M. T. O Núcleo de Avaliação Educacional no contexto da reorganização curricular. In. SÃO PAULO (Município). Secretaria Municipal de Educação. Subsídios 4 - Avaliação para a aprendizagem: externa e em larga escala. São Paulo: SME/DOT, 2015. p. 37-40.

FERRÃO, M. E.; BELTRÃO, K. I.; SANTOS, D. P. Políticas de não-repetência e a qualidade da educação: evidências obtidas a partir da modelagem dos dados da 4a série do SAEB-99. Estudos em avaliação educacional, São Paulo, n. 26, p. 47-74, 2002.

FREITAS, D. N. T. A concepção de educação básica no discurso político-normativo brasileiro. In: FREITAS, D. N. T.; FEDATTO, N. A. S. Educação básica: discursos e práticas político-normativas e interpretativas. Dourados, MS: Editora UFGD, 2008. p. 33-53.

FREITAS, L. C. Ciclo, seriação e avaliação: confronto entre duas lógicas. São Paulo: Moderna, 2003.

GLÓRIA, D. M. A. A escola dos que passam sem saber: a prática da não retenção escolar na narrativa de alunos e familiares. Revista Brasileira de Educação, Rio de Janeiro, n. 22, p. 61-76, 2003.

JACOMINI, M. A. Por que a maioria dos pais e alunos defende a reprovação? Cadernos de Pesquisa, São Paulo, v. 40, n. 141, p. 895-919, 2010.

JEFRREY, D. C. O regime de progressão continuada: o caso paulista (1998-2004). São Paulo: Editora UNESP, 2011.

MAINARDES, J.; STREMEL, S. Avaliação da aprendizagem no contexto dos ciclos: reflexões sobre seus elementos essenciais. Imagens da Educação, Maringá, v. 1, n. 3, p. 53-64, 2011.

MAINARDES, J. Abordagem do ciclo de políticas: uma contribuição para a análise de políticas educacionais. Educação e Sociedade, Campinas, v. 27, n. 94, p. 47-69, 2006.

MAINARDES, J. Reinterpretando os ciclos de aprendizagem. São Paulo: Cortez, 2007. 
PARO, V. H. Reprovar escolar: renuncia à educação. São Paulo: Editora Xamã, 2001.

PATTO, M. H. S. O fracasso escolar como objeto de estudo: anotações sobre as características de um discurso. Cadernos de pesquisa, São Paulo, v. 65, p. 72-77, 1988.

REBELO, J. A. S. Efeitos da retenção escolar, segundo os estudos científicos, e orientações para uma intervenção eficaz: Uma revisão. Revista Portuguesa de Pedagogia, Coimbra, PT, n. 43-1, p. 27-52, 2009.

RIBEIRO, S. C. A pedagogia da repetência. Estudos avançados, São Paulo, v. 5, n. 12, p. 07-21,1991.

SÃO PAULO (Município). DECRETO № 54.452, de 10 de outubro de 2013a Institui, na Secretaria Municipal de Educação, o Programa de Reorganização Curricular e Administrativa, Ampliação e Fortalecimento da Rede Municipal de Ensino - Mais Educação São Paulo. Disponível em:<http://portal.sme.prefeitura.sp.gov.br/Portals/1/Files/7077.pdf>. Acesso em: 20 maio 2015.

SÃO PAULO (Município). Secretaria Municipal de Educação. Considerações sobre o currículo e os direitos de aprendizagem e desenvolvimento dos alunos na rede municipal de São Paulo: contexto e perspectivas. Abril de 2013b. Disponível em: <http://portal.sme.prefeitura.sp.gov.br/programamais-educacao-sao-paulo-1/>. Acesso em: 22 dez. 2015.

SÃO PAULO (Município). PORTARIA 5.930, de 14 de outubro de 2013c. Regulamenta o Decreto no 54.452, de 10/10/13, que institui, na Secretaria Municipal de Educação, o Programa de Reorganização Curricular e Administrativa, Ampliação e Fortalecimento da Rede Municipal de Ensino de São Paulo"Mais Educação São Paulo". Disponível em: $<$ http://www3.prefeitura.sp.gov.br/cadlem/secretarias/negocios juridicos/cadlem/integra.asp?alt=1 5102013P\%20059302013SME>. Acesso em: 10 jan. de 2015.

SÃO PAULO (Município). Secretaria Municipal de Educação. Avaliação na Educação Infantil: aprimorando os olhares. São Paulo: SME/DOT, dezembro 2013d. 48p.

SÃO PAULO (Município). Secretaria Municipal de Educação. Nota Técnica 22 Sobre a avaliação para a aprendizagem no ensino fundamental, incluindo a modalidade educação de jovens e adultos e no ensino médio. Outubro 2013e. Disponível em: $<$ http://www.sinpeem.com.br/lermais materias.php?cd materias=8218>. Acesso em: 22 dez. 2015.

SÃO PAULO (Município). Secretaria Municipal de Educação. Programa de Reorganização Curricular e Administrativa, Ampliação e Fortalecimento da Rede Municipal de Ensino de São Paulo (minuta da consulta pública). Agosto 2013f. Disponível em: <http://portal.sme.prefeitura.sp.gov.br/programamais-educacao-sao-paulo-1/>. Acesso em: 22 dez. 2015.

SÃO PAULO (Município). PORTARIA 1.224, de 10 de fevereiro de 2014a. "Institui o Sistema de Gestão Pedagógica - SGP no âmbito da Rede Municipal de Ensino de São Paulo e dá outras providencias". Disponível em: $<$ http://portalsme.prefeitura.sp.gov.br/Projetos/ie/Documentos/Portarias/PORTARIA\%20N\%C2\%BA \%201224.pdf>. Acesso em: 22 dez. 2015.

SÃO PAULO (Município). Secretaria Municipal de Educação. Subsídios 2- Sistema de Gestão Pedagógica - SGP e a Avaliação para aprendizagem. São Paulo: SME/DOT, 2014b. 152 p. 
SÃO PAULO (Município). Secretaria Municipal de Educação. Orientação normativa no 01: avaliação na educação infantil aprimorando os olhares. São Paulo: SME / DOT, 2014c. 48p.

SÃO PAULO (Município). PORTARIA 3.611, de 29 de maio de 2015a- Institui a "Prova Mais Educação", instrumento de avaliação bimestral nas Unidades Educacionais que mantêm o Ensino fundamental da Rede Municipal de Ensino de São Paulo, e dá outras providências. Disponível em: $<$ http://www.sinesp.org.br/index.php?option=com content\&view=article\&id=13111:-portaria-no3611-de-29-de-maio-de-2015-institui-a-prova-mais-educacao-instrumento-de-avaliacao-bimestralnas-unidades-educacionais-\&catid=48:saiu-no-doc\&ltemid=221>. Acesso em: 10 ju. 2015.

SÃO PAULO (Município). Secretaria Municipal de Educação. Subsídios 4 - Avaliação para a aprendizagem: externa e em larga escala. São Paulo: SME/DOT, 2015b. 64 p.

SHIROMA, E. O. et al. Decifrar textos para compreender a política: subsídios teórico-metodológico para análise de documentos. Perspectiva. Florianópolis, v. 23, n. 2, p. 427-446, 2005.

SILVA, M. S. P.; CARVALHO, L. S. Faces do gerencialismo em educação no contexto da nova gestão pública. Revista Educação em Questão, Natal, RN, v. 50, n. 36, p. 211-239, 2014.

SILVA, M. A. Qualidade social da educação pública: algumas aproximações. Cadernos Cedes, Campinas, v. 29, n. 78, p. 216-226, 2009.

SOUSA, S. Z. Avaliação, ciclos e qualidade do Ensino fundamental: uma relação a ser construída. Estudos avançados, São Paulo, v. 21, n. 60, p. 27-44, 2007.

SOUSA, S. Z. Concepções de qualidade educação básica forjadas por meio de avaliações em larga escala. Avaliação. São Paulo, v. 19, n. 2, p. 407-420, 2014.

TAKAHASHI, F. Educadores apontam que alunos perderam a disciplina porque sabem que a reprovação é quase impossível. Folha de São Paulo, São Paulo, 15 ago. 2013. Disponível em: $<$ http://www.cpp.org.br/index.php/comunicacao/pontodevista/item/179-proposta-do-prefeitoagrada-docente-que-quer-mais-poderes $>$. Acesso em: 30 jun. 2013.

VIÉGAS, L. S. Progressão continuada em uma perspectiva histórica. Revista brasileira de estudos pedagógicos, Brasília, DF, v. 90, n. 225, p. 489-510, 2009. 